\title{
Pilot Study of the Teaching of Critical Thinking Skills and Creative Talents for Biochemistry Students at University
}

\author{
LO Fai-hang \\ Biochemistry Programme, School of Life Sciences, \\ The Chinese University of Hong Kong, \\ Hong Kong, China \\ lofaihang@cuhk.edu.hk
}

\begin{abstract}
A reform of the education system was introduced in Hong Kong in the past few years. Secondary School students entering university were observed to be highly diverse in terms of their academic backgrounds than ever before. Our previous studies had revealed that students under the new education system emphasized more on factual knowledge; however, their views on generic skills, such as critical thinking skills and creative talents, apparently declined (when compared with students before the reform). In this pilot study, we conducted five preliminary surveys studying the teaching effectiveness of critical thinking skills and creative talents among university students major in Biochemistry. Lectures and in-class activities were designed and conducted to promote the critical thinking skills and creative talents among the students between 2011 and 2015. Our preliminary findings suggested that the increased attendance of lectures and the increased participation of in-class activities were positively correlated to the performance and the confidence of the students' critical thinking skills, although no statistically significant data was obtained at this stage. Interestingly, our preliminary findings also implicated with statistical significance that the lectures and in-class activities were positively correlated to the change in the attitudes of the students on the importance of creative talents for the study of life science and the assessment of the their creative talents. Taken together, our preliminary findings built up a foundation for us to further expand and optimize our study based on the current lecture design and inclass activity arrangement. In the long run, it is envisaged that the critical thinking skills and creative talents could be promoted among the students under the new education system.
\end{abstract}

Keywords-life science; biochemistry; lecture; in-class activity; critical thinking skills; creativity; knowledge-based society

\section{INTRODUCTION}

Secondary School and University education in Hong Kong has undergone major reform in the past few years [1]. A new public examination called Hong Kong Diploma of Secondary Education (HKDSE) has been introduced in 2012 [2]; meanwhile, a four-year bachelor curriculum was implemented at universities [3]. Secondary School students entered universities one year earlier than before.

In 2005, the Education and Manpower Bureau of the Government of Hong Kong Special Administrative Region announced the new curricula of Secondary School with key emphases on 'Whole-Person-Development', where 'Liberal Studies' was repositioned as a compulsory core subject for all Secondary School students accompanied with the curricular changes in traditional science subjects, such as Biology and Chemistry [3]. As we anticipated that the academic backgrounds of students, who took HKDSE, would become more diverse than ever, we conducted a series surveys on the students to compare their expectations of university education with students in the old education system [4].

The findings indicated that, when compared with students before the reform, there was apparent changes in the attitudes among the students in specific areas, for example, students taking HKDSE considered it was the most important to study factual knowledge at university; while the learning of generic skills, such as critical thinking skills and creative talents, was ranked as less important [4]. Moreover, the assessments of critical thinking skills and creative talents were the lesssupported criteria of their learning outcomes, when compared with the test for factual knowledge [4]. Our findings also suggested that the overall self-satisfaction of the students was remarkably lower, for instance, there was an overall decline in the self-satisfaction in critical thinking skills and creative talents by over $15 \%$ among the students taking HKDSE [4]. These findings could indicate some potential challenge for our students to excel their critical thinking skills and creative talents, which are very important for the success in the knowledge-based society [5]. In the present study, we conducted some surveys related to the teaching of critical thinking skills and creative talents among Life Sciences students major in Biochemistry.

\section{METHODS}

\section{A. Overview}

We conducted five surveys between 2011 and 2015. Four surveys (along four consecutive academic years from 2011 to 2015) were related to the teaching of critical thinking skills in a Biochemistry course with 15 to 26 students and the other survey (2014-15) was related to the learning of creative talents in another Biochemistry course with 32 students. 


\section{B. Survey on Critical Thinking Skills}

The duration of the surveys was four weeks; where the students were asked to complete a questionnaire at the beginning and at the end of the period. The questionnaire consisted of nine true-or-false questions focusing on inductive and deductive logic in the context of Endocrinology. During the four-week period, there were 12 lectures with a total of 20 (in 2011 to 2012) and 25 (from 2012 to 2015) in-class activities delivering the relevant critical thinking skills. At the end of the survey, students were also asked to report how many lectures they attended and how many in-class activities they fully completed. 'Performance Index' (PI) was designed and calculated based on the survey results, where there was +1 point for each correct answer and -1 point for each incorrect answer. In practice, the highest possible PI is +9 ; while the lowest possible value will be -9 . On the other hand, 'Confidence Index' (CI) was designed and calculated according to the formula,

$$
\mathrm{CI}=(\mathrm{n}-\mathrm{x}) / \mathrm{n}
$$

where $\mathrm{n}$ is the number of questions, that is, nine; $\mathrm{x}$ is the total number of unsure answer. When a student was not sure if the answer was true or false, s/he might select the third 'Not Sure' option, for example, if the student was unsure for one particular question, CI $=(9-1) / 9=0.89$, no matter the answers of the other eight questions were correct or not. If the student was unsure for two questions, then $\mathrm{CI}=(9-2) / 9=0.77$, and so on

\section{Survey on Creative Talents}

The duration of the survey was 13 weeks. The students were asked to complete a questionnaire at the end of the period, where they were also asked to report how many lectures they attended and how many workshop and in-class activities they fully completed. The questionnaire consisted of seven pairs of statements interviewing their opinions about their creative talents, where they were asked to select 'Strongly Disagree' (with one point), 'Disagree' (with two points), 'Neutral' (with three points), 'Agree' (with four points), and 'Strong Disagree' (with five points). Each pair of statements consisted of one positively-framed description and a negatively-framed description [5]; the score difference between the answer of the positive and negative description will be calculated and presented. In practice, the net score will be large if the answers of both descriptions were consistent, and vice versa.

\section{RESULTS}

\section{A. Teaching of Critical Thinking Skills}

To evaluate the effectiveness of the teaching, 'Performance Index' (PI) was designed to reflect on the critical thinking skills of the students. The PI at the beginning and at the end of the survey, among students with $100 \%$ and $>80 \%$ self-report lecture attendance, and among students with $100 \%$ and $>80 \%$ self-report in-class activity completion was analyzed and presented. The average values of the four surveys were presented in Fig. 1. It was observed that the four-week-lecture teaching could generally increase the PI of the students, in particular, for students who attended all the lectures, though the increase was not statistically significant. On the other hand, to evaluate the confidence of the students about their critical thinking skills, 'Confidence Index' (CI) was designed. According to Fig. 2., the four-week-lecture teaching was also able to increase the CI in general, where the most significant improvement of CI was observed in students with $100 \%$ lecture attendance.

\section{B. Teaching of Creative Talents}

To evaluate the effectiveness of the teaching of creative talents, students were surveyed at the end of a 13-week course incorporated with a total of eight workshop and in-class activities. There were seven questions in the survey related to their view of creative talents from different perspectives. Our preliminary findings indicated that with the increase in the participation of in-class activities, the proportion of students supporting the assessment of their creative talents increased with statistical significance (Fig. 3.); in the meantime, when compared with students with lecture attendance ranging from $50 \%$ to $80 \%$, for students who attended all the lectures, there was a significant increase in the proportion who agreed about the importance of creative talents for their study of life science (Fig. 4.).

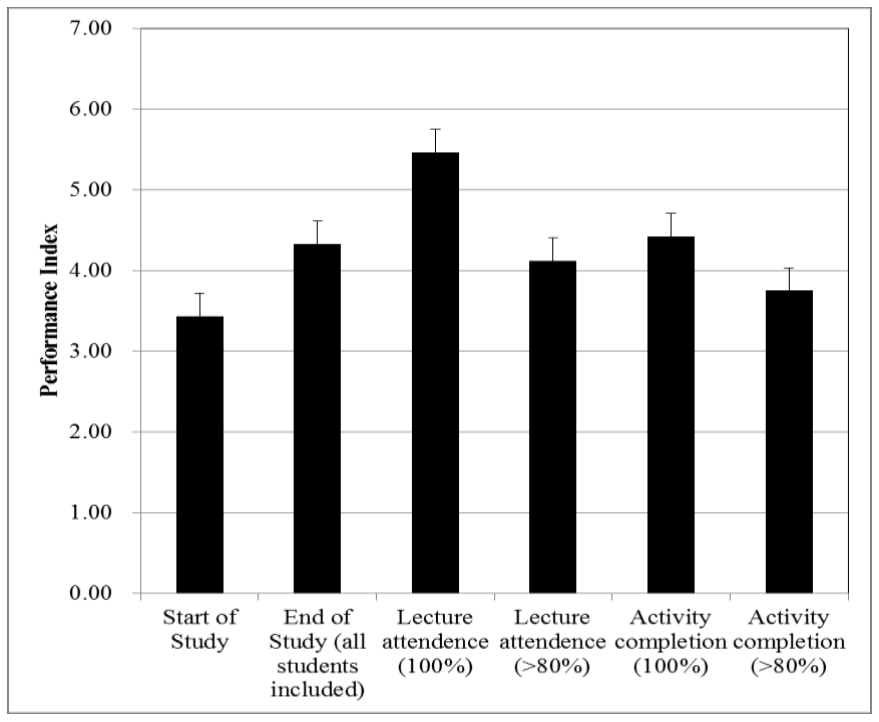

Fig. 1. Performance Index of the critical thinking skills among students surveyed. Four surveys were conducted between 2011 and 2015. The students were asked to complete a questionnair with nine true-or-false questions at the beginning and at the end of the survey to evaluate their critical thinking skills. The students were also requested to report on their attendence to lectures and participation of in-class activities. Performance Index (see Methods Section) was designed to reflect and compare about the critical thinking skills of the students with different lecture attendence and in-class activity participation. 


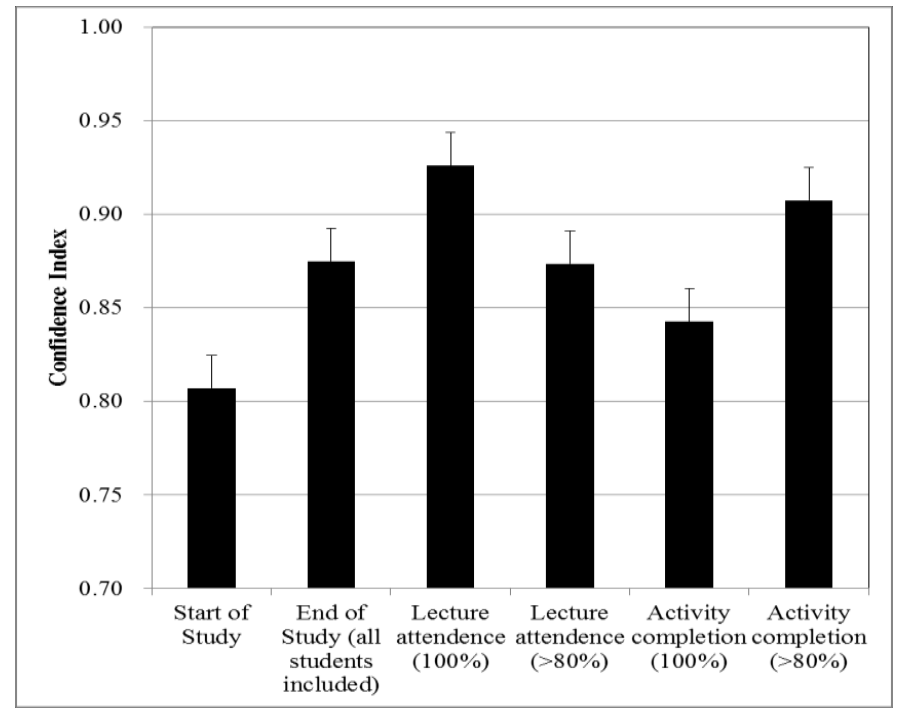

Fig. 2. Confidence Index of the critical thinking skills among students surveyed. Four surveys were conducted between 2011 and 2015. The students were asked to complete a questionnair with nine true-or-false questions at the beginning and at the end of the survey to evaluate their critical thinking skills. When the students were unsure about the answer of a particular question, s/he might select the answer as 'Not Sure'. The students were also requested to report on their attendence to lectures and participation of in-class activities. Confidence Index (see Methods Section) was designed to reflect on the proportion of unsure answers, and thus, compare about the confidence of students' critical thinking skills with different lecture attendence and in-class activity participation.

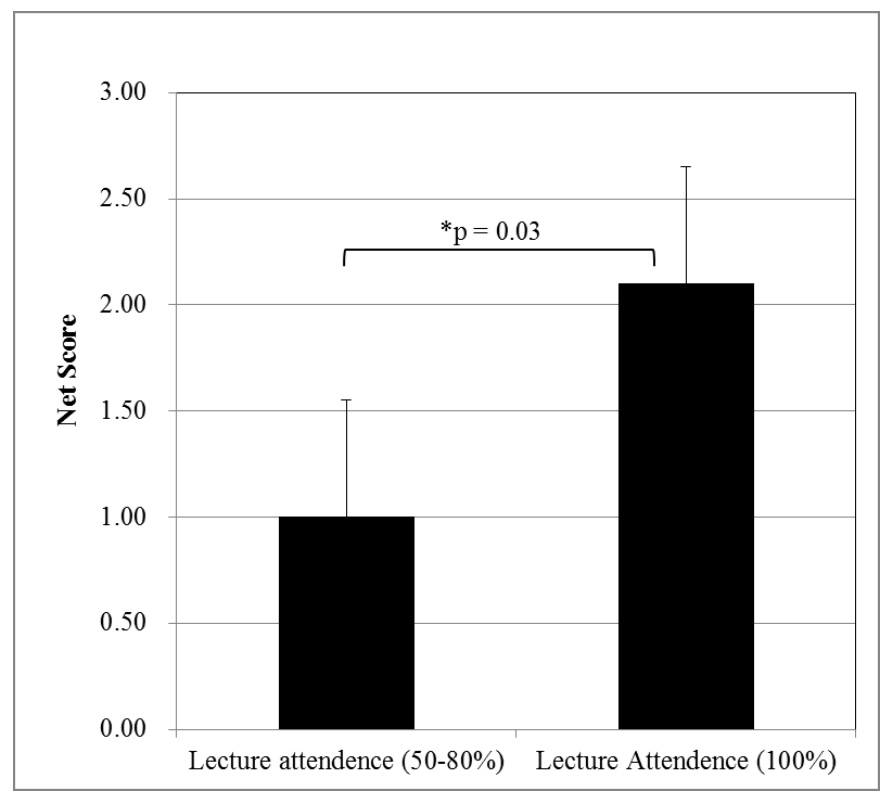

Fig. 3. Students' view on the importance of creative talents for the study of life science. A survey was conducted between 2014 and 2015. The students were asked to complete a questionnair with seven statements describing their view on their creative talents at the end of a 13-week course incoporated with eight workshop and in-class activities relavent to creative talent development. The students were also requested to report on their attendence to lectures and participation of in-class activities. The score difference (see Method Section) was calculated to reflected on the degree that student agreed about the description.

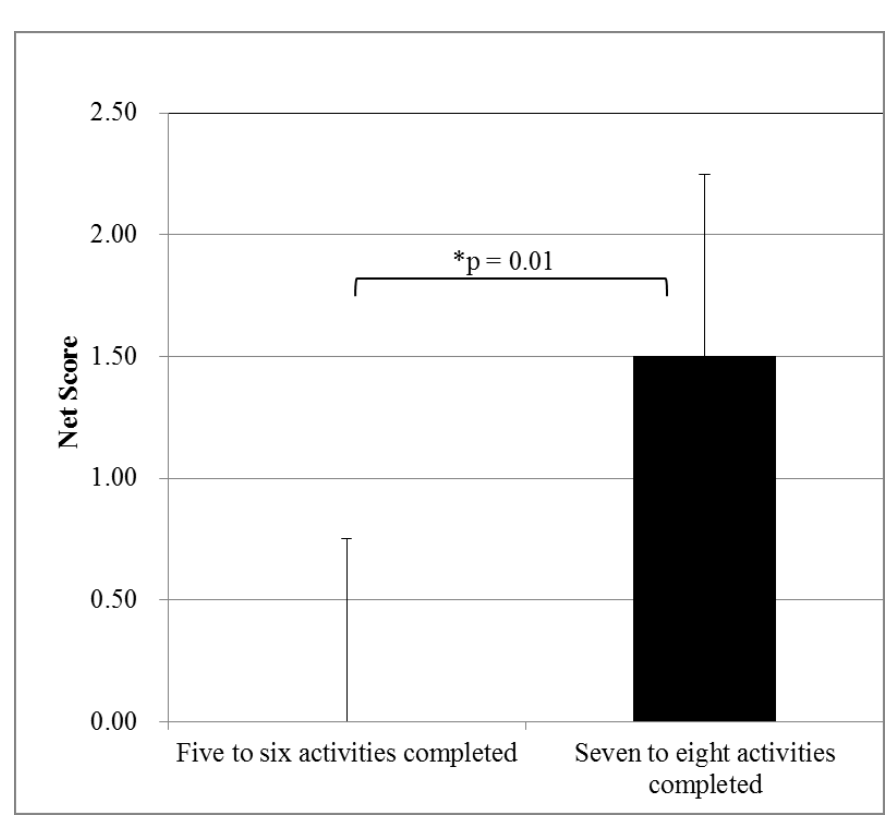

Fig. 4. Students' view on the assessment of creative talents. A survey was conducted between 2014 and 2015. The students were asked to complete a questionnair with seven statements describing their view on their creative talents at the end of a 13-week course incoporated with eight workshop and in-class activities relavent to creative talent development. The students were also requested to report on their attendence to lectures and participation of inclass activities. The score difference (see Method Section) was calculated to reflected on the degree that student agreed about the description.

\section{Limitations of the Preliminary Data}

Since the present study focused on students major in Biochemistry at University, the critical thinking skills and creative talents were applied in specific contexts of biochemistry and endocrinology. In this sense, well validated questionnaire related to general critical thinking skills and creativity was not used at the present stage of the study. Moreover, the self-reports of lecture attendance and in-class activity participation by the students might not be $100 \%$ accurate and reliable.

Another major limitation, especially for the surveys of critical thinking skills, was the small sample size: with the practical difficulty to recruit students to attend all the lectures and complete all the workshop and in-class activities, the small sample size could help explain the statistical insignificant and slightly inconsistent data; for the CI results in particular, we were not able to satisfactorily explain the observation why the CI was higher in students completing $>80 \%$ of in-class activities than those completed $100 \%$. One of the possible explanations was that confidence was subjective perception, which might not be linearly translated into numerical data. Or, this observation was a reflection of Dr Albert Einstein's famous quotes 'the more I learn, the more I realize how much I don't know'.

The limitations for the survey of creative talents among the students included limited number of survey conducted, the lack of survey at the beginning of the lectures and in-class activities (such that we were unable to confirm whether the observation was linked to a belief change rather than the fact that students, 
who believed in the importance of creative talents, attended more lectures and participated more in-class activities); as a result, the availability of relevant data for analysis was limited. All the limitations should be overcome in the next stage of study.

\section{DISCUSSION AND FUTURE PROSPECTIVES}

As implicated in our previous study [4], we focused on the teaching of critical thinking skills and creative talents of Biochemistry students at university. The present pilot study provided useful information for future planning. One of the important implications of the findings about the teaching of critical thinking skills was that the design and implementation of the course and in-class activities coincided with the elevating trends of the critical thinking skills of the students in terms of the PI and CI (Fig. 1. and Fig. 2.). Although the changes in PI and CI were not statistically significant, this observation provided the foundation for us to expand and optimize the study to larger scale based on the current course design and in-class activity arrangement. Well validated questionnaire for general critical thinking skills will also be incorporated in the next stage of study [7].

Regarding the teaching of creative talents, the preliminary data was encouraging. According to our previous study [4], students apparently indicated that creative talents were not important for them and they did not generally support the assessment of their creative talents to measure their learning progress. Our data suggested that the increase in lecture attendance and in-class activity participation was positively correlated to the belief change among students, for example, more students believed that creative talents were important for their study of life science (Fig. 3.). In the meantime, more students showed their support to the assessment of their creative talents during the learning of life science (Fig. 4.). The data implicated that the design of the lecture and in-class activities could induce desired behavioural as well as belief change favouring creative talents among the students [8]. Similar surveys with optimization will be conducted in the next stage of study. The optimization include survey before the start of lecture and in-class activities, the use of well validated questionnaire [9] for the creative talents of the students to collect more relevant and useful results.

Another point to note was that, according to the preliminary data, students should be encouraged to attend lectures and to participate in-class activities as much as possible for the best improvement of both of the critical thinking skills and creative talents. Although the efficacy of distance learning has been supported by many studies, self-study might not be as effective as traditional classroom teaching $[10,11]$. That observation might be contradictory to the habits of many university students in Hong Kong. Effort should be made to encourage students to go to classes and acquire skills which cannot be replaced by distance learning or self-study [11]. The long term strategy is that lectures and courses will be designed and conducted to promote optimal behavioral and belief change in the learning habits among the students to better survive and succeed in the highly competitive knowledge-based society like Hong Kong.

\section{REFERENCES}

[1] "Reform Proposal for the Education System in Hong Kong," Education Bureau, The Government of Hong Kong Special Administrative Region. September 2000.

[2] “About HKDSE," Hong Kong Examination and Assessment Authority. 2008 .

[3] "A Holistic Review of the Hong Kong School Curriculum Proposed Reforms," Curriculum Development Council, The Government of Hong Kong Special Administrative Region. March 2014.

[4] F.H. Lo, "Expectations of life science students in university from two education systems," Proceedings of 2014 International Conference on Education Science and Human Development, November 2014, indexed by CPCI-SSH.

[5] J. Sauro and J.R. Lewis, "When Designing Usability Questionnaires, Does It Hurt to Be Positive?" Proceedings of 2011 ACM CHI Conference on Human Factors in Computing Systems, May 2011.

[6] D. Kember and D.Y.P. Leung, "The Influence of the Teaching and Learning Environment on the Development of Generic Capabilities Needed for a Knowledge-Based Society." Learn Environ. Res., vol. 8, pp. 245-266, November 2005.

[7] T. Neil and E. Brittney, "Student Performance on the California Critical Thinking Skills Test,” AELJ, vol. 16, pp. S25-98, November 2012.

[8] I. Ajzen and T.J. Madden1, "Prediction of goal-directed behavior: Attitudes, intentions, and perceived behavioral control.” J. Exp. Soc. Psychol., vol. 22, pp. 453-474, September 1986.

[9] L. K. Mishra and A. P. Singh, "Creative Behaviour Questionnaire: Assessing the Ability of Managers to Produce Creative Ideas," JIAAP, vol. 36, pp. 115-121, January 2010.

[10] D. Zhang, J.L. Zhao, L. Zhou and J.F. Nunamaker, "Can E-Learning Replace Classroom Learning?” Commun. ACM, vol. 47, pp. 75-79, May 2004.

[11] M. Allen , J. Bourhis , N. Burrell and E. Mabry, "Comparing Student Satisfaction With Distance Education to Traditional Classrooms in Higher Education: A Meta-Analysis." AJDE, vol. 16, pp. 83-97, June 2010 . 